\title{
Study of serum uric acid level among stroke patients in a tertiary care hospital
}

\author{
Chandrayya Achanna Kante
}

Associate Professor, Department of General Medicine, Dr Ulhas Patil Medical College, Jalgaon, Maharashtra, INDIA. Email: drcakante@gmail.com

\begin{abstract}
Background: Stroke is a major global public health problem. Higher risk of stroke incidence and mortality was reported in cases of hyperunicemia in some studies while contrary to this, other studies have advocated uric acid to be neuroprotective due to its anti-oxidant action. Considering these conflicting data, present study is designed to study the association between serum uric acid levels and stroke at a tertiary care hospital. Material and Methods: Present study was prospective, observational study, conducted in patients with ischemic stroke confirmed by CT scan of brain, presenting within 72 hours of onset of symptom. Statistical Analysis was done during SPSS Software for Windows Ver. 23. The data obtained was expressed as mean \pm standard deviation. Correlation was computed by Pearson's correlation coefficient. Results: In present study 82 patients with stroke were included. Most common age group was 61-70 years (35\%). Male to female ratio was 1.7:1. 30\% patients had hyperuricemia (serum uric acid $>7 \mathrm{mg}$ ). Hyperuricemia was noted in $41 \%$ smokers, $65 \%$ alcoholics, $55 \%$ diabetics, $79 \%$ with history of cardiovascular disease, $64 \%$ with family history of stroke and $41 \%$ patients with hypertension. Mean serum uric acid (SUA) levels was $4.36 \pm 2.04 \mathrm{mg} / \mathrm{dl}$. A positive correlation. (Spearman's Correlation coefficient, $r=+0.6979$ ) of serum uric acid (SUA) levels was noted with severity of stroke. Conclusion: Serum uric acid levels were significantly elevated in patients with acute ischemic stroke. Also serum uric acid levels were significantly higher among hypertensive and diabetic patients with stroke compared to their counterparts.

Key Words: acute ischemic stroke, uric acid, hyperuricemia, hypertension, smoking
\end{abstract}

*Address for Correspondence:

Dr Chandrayya Achanna Kante, Associate Professor, Department of General Medicine, Dr Ulhas Patil Medical College, Jalgaon,

Maharashtra, INDIA.

Email: drcakante@gmail.com

Received Date: 20/11/2019 Revised Date: 19/12/2019 Accepted Date: 11/01/2020

DOI: https://doi.org/10.26611/10211626

This work is licensed under a Creative Commons Attribution-NonCommercial 4.0 International License. (cc)) EY-No

\begin{tabular}{|l|l|}
\hline \multicolumn{2}{|c|}{ Access this article online } \\
\hline Quick Response Code: & Website: \\
& www.medpulse.in \\
\hline
\end{tabular}

\section{INTRODUCTION}

Stroke is a major global public health problem. Due to significant demographic, economic and epidemiological transition an increase in life expectancy and consequently an increase in ageing population is noted in India. Reliable morbidity and mortality estimates for stroke in India are very limited. ${ }^{1}$ Various risk factors for stroke such as, high blood pressure, previous stroke or transient ischaemic attack, high cholesterol, heart disease, diabetes and sickle cell disease are described. Lifestyle related conditions like unhealthy diet, lack of physical exercise, obesity, smoking and excessive alcohol consumption were also attributed to the causation of stroke. ${ }^{2}$ Uric acid is the final breakdown product of purine degradation in humans. In adulthood, concentrations rise steadily over time and vary with height, body weight, blood pressure, renal function, and alcohol intake. ${ }^{3}$ Uric acid is one of the major aqueous antioxidant in the human beings and constitutes approximately one half the antioxidant capacity of plasma. ${ }^{4}$ But it can work as a pro-oxidant under certain circumstances, particularly if the levels of other antioxidants (like ascorbate) are low, thus predisposes to the development of hypertension and vascular disease. Overwhelming evidence suggests that hyperuricemia is linked to obesity, hypertension, reduced HDL cholesterol, hypertriglyceridemia, hyperinsulinemia and reduced insulin sensitivity, components of the metabolic syndrome, chronic kidney disease, etc. ${ }^{5}$ There is agreement on the association between high SUA levels and cardiovascular-related mortality in the general population. ${ }^{6}$ But association of hyperuricemia and stroke is not evaluated at larger scale. Higher risk of stroke incidence and mortality was reported in cases of hyperunicemia in some studies ${ }^{7,8}$ while contrary to this, other studies have 
advocated uric acid to be neuroprotective due to its antioxidant action. ${ }^{9,10}$ Considering these conflicting data, present study is designed to study the association between serum uric acid levels and stroke at a tertiary care hospital.

\section{MATERIAL AND METHODS}

Present study was prospective, observational study, conducted in the Department of General Medicine, Dr Ulhas Patil Medical College, Jalgaon. Study duration was 1 year (June 2019 to May 2020). Study was approved by institutional ethics committee.

Inclusion Criteria:

Patients with ischemic stroke (defined as a syndrome of rapidly developing clinical signs of focal or global neurological disturbance lasting for more than 24 hours), confirmed by CT scan of brain, presenting within 72 hours of onset of symptom.

Exclusion Criteria:

1. Age less than 40 years..

2. Other co-morbid conditions such as - acute myocardial infarction, hepatic encephalopathy, septicemia, chronic renal failure and gout.

3. Patients receiving drugs which may alter the level of uric acid (like thiazide, allopurinol) and iron or any antioxidant

4. Patients with Hemorrhagic stroke, old cases of stroke, prior history of stroke and strokes secondary to trauma, neoplasm, vasculitis and infection.

5. Patients who received thrombolytic agent, admitted within $3 \mathrm{~h}$ and had thrombolysis, diuretic or any other investigational drug during their hospital stay.

Study was explained to relatives and a written informed consent was taken from them. Detailed history taking and clinical examination was undertaken for every patient at admission. All routine investigations like complete hemogram, Blood glucose, liver and kidney function test, lipid profile, electrolytes, urine exam ECG were done. Serum uric acid was estimated within 24 Hours of hospitalization by enzymatic uricase method. Blood was drawn on admission for all the biochemical parameters we considered for statistical analysis to avoid change in serum uric acid level due to subsequent administration of drug or intravenous fluid. Beside these, other biochemical testing and imaging study were done as per requirement of individual patient. CT scan of brain was done in all patients after hospitalization. The NIH Stroke Scale (NIHSS) ${ }^{11}$ was used as a diagnostic method for quickly assessing the severity of a stroke experienced by a patient. Patients were categorized it into 5 categories:

\begin{tabular}{cc}
\hline Category & Score \\
\hline No stroke symptoms & 0 \\
Minor stroke & $1-4$ \\
Moderate stroke & $5-15$ \\
Moderate to severe stroke & $16-20$ \\
Severe stroke & $21-42$ \\
\hline
\end{tabular}

Statistical Analysis was done during SPSS Software for Windows Ver. 23. The data obtained was expressed as mean \pm standard deviation. Correlation was computed by Pearson's correlation coefficient.

\section{RESULTS}

In present study 82 patients with stroke were included. Most common age group was 61-70 years (35\%) followed by $51-60$ years $(26 \%)$ age group. Male patients $(62 \%)$ were more than female patients (38\%). Male to female ratio was $1.7: 1.30 \%$ patients had hyperuricemia (serum uric acid $>7$ $\mathrm{mg})$.

\begin{tabular}{cccccc}
\multicolumn{2}{l}{ Table 1: Distribution of cases according to age, and serum uric acid levels in patients with stroke } \\
\hline \multicolumn{2}{c}{$\begin{array}{c}\text { Age groups (in } \\
\text { years) }\end{array}$} & Total (\%) & \multicolumn{2}{c}{ Sex } & \multicolumn{2}{c}{ Serum uric acid levels } \\
\cline { 3 - 6 } & $5(6 \%)$ & $4(5 \%)$ & $1(1 \%)$ & $4(5 \%)$ & $1(1 \%)$ \\
\hline$<40$ & $9(11 \%)$ & $6(7 \%)$ & $3(4 \%)$ & $7(9 \%)$ & $2(2 \%)$ \\
$41-50$ & $21(26 \%)$ & $13(16 \%)$ & $8(10 \%)$ & $15(18 \%)$ & $6(7 \%)$ \\
$51-60$ & $29(35 \%)$ & $16(20 \%)$ & $13(16 \%)$ & $19(23 \%)$ & $10(12 \%)$ \\
$61-70$ & $17(21 \%)$ & $11(13 \%)$ & $6(7 \%)$ & $12(15 \%)$ & $5(6 \%)$ \\
$71-80$ & $1(1 \%)$ & $1(1 \%)$ & 0 & 0 & $1(1 \%)$ \\
$>81$ & 82 & $51(62 \%)$ & $31(38 \%)$ & $57(70 \%)$ & $25(30 \%)$ \\
\hline
\end{tabular}

Hyperuricemia was noted in $41 \%$ smokers, $65 \%$ alcoholics, $55 \%$ diabetics, $79 \%$ with History of cardiovascular disease and $64 \%$ with family history of stroke. In stroke patients hypertension was noted in $41 \%$ patients. Hyperuricemia was noted in $8 \%, 17 \%, 47 \%$ and $73 \%$ patients with normal blood pressure, pre hypertension, stage 1 hypertension and stage 2 hypertension respectively.

\begin{tabular}{|c|c|c|c|}
\hline \multirow[t]{2}{*}{ High risk factors } & \multicolumn{2}{|c|}{ Level of SUA } & \multirow[t]{2}{*}{ Total $(n=82)$} \\
\hline & $\leq 7 \mathrm{mg} / \mathrm{dl}(\%)$ & $>7 \mathrm{mg} / \mathrm{dl}(\%)$ & \\
\hline Smoker & $16(59 \%)$ & $11(41 \%)$ & $27(33 \%)$ \\
\hline Alcoholic & $6(35 \%)$ & $11(65 \%)$ & $17(21 \%)$ \\
\hline
\end{tabular}




\begin{tabular}{cccc}
\hline Diabetic & $14(45 \%)$ & $17(55 \%)$ & $31(38 \%)$ \\
Blood pressure & & & \\
Normal Blood pressure & $33(92 \%)$ & $3(8 \%)$ & $36(59 \%)$ \\
Pre hypertension & $10(83 \%)$ & $2(17 \%)$ & $12(59 \%)$ \\
Stage 1 hypertension & $10(53 \%)$ & $9(47 \%)$ & $19(23 \%)$ \\
Stage 2 hypertension & $4(27 \%)$ & $11(73 \%)$ & $15(18 \%)$ \\
History of cardiovascular disease & $4(21 \%)$ & $15(79 \%)$ & $19(23 \%)$ \\
Family history of stroke & $4(36 \%)$ & $7(64 \%)$ & $11(13 \%)$ \\
\hline
\end{tabular}

(Pre hypertension SBP-120-139 DBP-80-89, Stage 1 hypertension SBP-140-159 DBP-90-99 , Stage 2 hypertension $\mathrm{SBP}>160, \mathrm{DBP}>100$ ) In present study mean serum uric acid (SUA) levels was $4.36 \pm 2.04 \mathrm{mg} / \mathrm{dl}$. As per NIHSS scale severity cases presented with minor stroke (48\%) had mean SUA levels $4.12 \pm 0.36 \mathrm{mg} / \mathrm{dl}$, cases with Moderate stroke (32\%) had mean SUA levels $5.73 \pm 0.79 \mathrm{mg} / \mathrm{dl}$, cases with Moderate to severe stroke (16\%) had mean SUA levels $7.19 \pm$ $1.01 \mathrm{mg} / \mathrm{dl}$ and cases presented with Severe stroke (5\%) had mean SUA levels $8.18 \pm 1.52 \mathrm{mg} / \mathrm{dl}$. A positive correlation. (Spearman's Correlation coefficient, $r=+0.6979$ ) of serum uric acid (SUA) levels was noted with severity of stroke.

Table 3: Distribution of patients according to NIHSS scale severity

\begin{tabular}{ccccc}
\hline Score & Stroke severity & Number of patients (\%) & Mean SUA levels & Correlation parameters \\
\hline 0 & No stroke symptoms & 0 & 0 & $\mathrm{r}=+0.703$ \\
$1-4$ & Minor stroke & $39(48 \%)$ & $4.12 \pm 0.36 \mathrm{mg} / \mathrm{dl}$ & \\
$5-15$ & Moderate stroke & $26(32 \%)$ & $5.73 \pm 0.79 \mathrm{mg} / \mathrm{dl}$ & \\
$16-20$ & Moderate to severe stroke & $13(16 \%)$ & $7.19 \pm 1.01 \mathrm{mg} / \mathrm{dl}$ & \\
$21-42$ & Severe stroke & $4(5 \%)$ & $8.18 \pm 1.52 \mathrm{mg} / \mathrm{dl}$ & \\
\hline
\end{tabular}

\section{DISCUSSION}

In present study we investigated the prevalence of hyperuricaemia in stroke patients, the factors associated with hyperuricaemia and, whether there is any association between uric acid levels and stroke. In India, ischemic stroke accounts for $80 \%$ of all strokes, $10 \%-15 \%$ of strokes occur in people younger than 40 years and are mostly related to intracranial atherosclerosis. ${ }^{1}$ Stroke causes rapid deterioration in brain function due to alteration in the blood supply to the brain. Stroke is an acute emergency and can lead to progressive neurological damage, and eventually death, if not treated early. ${ }^{13}$ Elevated serum uric acid levels correlate with aging, male gender, hyperlipidaemia, diabetes mellitus, insulin resistance, glucose intolerance, obesity and hyperinsulinemia and may accelerate progression of hypertension and to end organ damage. ${ }^{12}$ Higher levels of serum uric acid levels were associated with a higher prevalence of carotid plaques which play an important role in the causation of ischemic cerebrovascular events in men. ${ }^{14}$ In a study, Yadav SK et al.., ${ }^{15}$ noted $28.33 \%$ (male $30.06 \%$, female $26.61 \%$ ). prevalence of hyperuricemia among the patients with stroke. Similar results were noted in present study. Yu-Fang Wang et al... ${ }^{16}$ analysed the outcomes of 1166 patients with ischaemic stroke. Mean age was $64.48 \pm 13.35$ year, ( in male patients $62.65 \pm 13.10$ years and in female patients $67.54 \pm 13.22$ years). Similar results were noted in present study. In present study, male to female ratio was 1.7:1. Zheng et al.. ${ }^{17}$ and Kawabe et al.. ${ }^{18}$ in their study confirmed similar findings. Female sex hormone estrogen lessens circulation of UA in women, and it facilitates renal urate clearance and reduction of tubular urate postsecretory reabsorption. Bhadraj et al.., ${ }^{19}$ noted significantly higher levels of uric acid in men with stroke as compared to control population. Uric acid levels also correlated significantly with stroke severity, increased uric acid levels being associated with greater initial stroke severity. ${ }^{19}$ Shah $\mathrm{H}$ assessed serum uric acid levels with NIHSS scale and observed a positive correlation. (Correlation coefficient, $\mathrm{r}=+0.6979$ ). Mean SUA levels $3.69 \pm 0.12 \mathrm{mg} / \mathrm{dl}, 5.82 \pm 0.4 \mathrm{mg} / \mathrm{dl}, 7.14 \pm 0.86 \mathrm{mg} / \mathrm{dl}$ and $8.4 \pm 1.2 \mathrm{mg} / \mathrm{dl}$ in minor, moderate, moderate to severe and severe stroke patients respectively. ${ }^{20}$ Similar results were noted in present study. In a study by Jiaqi et al.. from the Circulatory Risk in Communities Study in a general Japanese population, noted that an elevated SUA level is an independent predictor for total and ischemic strokes in women but not in men in a general Japanese population. ${ }^{21}$ Simialarly Karagiannis et al.., ${ }^{22}$ observed independent relationship between higher SUA levels on admission and death. In a systematic review involving of 16 cohort studies involving over 238,000 subjects that hyperuricaemia was significantly associated with a higher risk for stroke incidence and stroke mortality compared with normouricaemia. ${ }^{23}$ Previous studies have suggested that potential mechanisms suggested for association between hyperuricemia and development of stroke include enhancing lipid peroxidation and platelet adhesiveness, stimulating vascular smooth cell proliferation, causing vascular inflammation, damaging endothelial cells, and accelerating atherosclerosis. ${ }^{24}$ In present study due to small sample size, precise association between stroke and hyperuricemia can't commented. Long term case control studies are needed to describe the association between them. If hyperuricemia is identified as an etiological agent in the pathogenesis of stroke, therapeutically reduction 
could contribute to reduced morbidity and mortality due to stroke. Early identification of individual at risk could be of help in prevention of stroke. Also identification of potential prognostic factors for ischaemic stroke may enable better prediction for outcome and conducting early interventions may improve the prognosis.

\section{CONCLUSION}

Serum uric acid levels were significantly elevated in patients with acute ischemic stroke. Also serum uric acid levels were significantly higher among hypertensive and diabetic patients with stroke compared to their counterparts.

\section{REFERENCES}

1. Kamalakannan SK, Gudlavalleti ASV, Murthy Gudlavalleti VS, Goenka S, Kuper H. Challenges in understanding the epidemiology of acquired brain injury in India. Ann Indian Acad Neurol 2015; 18 : 66-70.

2. O'Donnell MJ, Xavier D, Liu L et al.. Risk factors for ischaemic and intracerebral haemorrhagic stroke in 22 countries (the Interstroke study): a case-control study. The Lancet 2010; 376 (9735): 112-23.

3. Burns CM, Wortmann RL. Disorders of purine and pyrimidine metabolism. In: Kasper D, Fauci A, Hauser S, et al., eds. Harrison's principles of internal medicine. 19th edn. McGraw-Hill Education 2015: p. 2533.

4. E. Fabbrini,M. Serafini, I. Colic Baric, S. L.Hazen, and S. Klein, "Effect of plasma uric acid on antioxidant capacity, oxidative stress, and insulin sensitivity in obese subjects," Diabetes, vol. 63, no. 3, pp. 976-981, 2014.

5. Kuwabara M. Hyperuricemia, cardiovascular disease, and hypertension. Pulse. 2016;3:242-52.

6. Ahmad MI, Dutta A, Anees MA, et al.. Interrelations Between Serum Uric Acid, Silent Myocardial Infarction, and Mortality in the General Population. Am J Cardiol. 2019;123:882-888

7. Bhadraj, Makor DS, Seth S, et al.. Uric Acid in men with acute stroke. Int J Interdis and Multidisci Studies 2015; 2(5): 146-52.

8. Rajeshwar K, Subash K, Venkaties Rao A, et al.. Association of Serum Uric Acid level with Ischemic Stroke, Stroke Subtypes and Clinical Outcome. Neurology Asia 2013; 18(4) : 34

9. Heo SH, Lee Sh. High levels of Serum Uric Acid are associated with silent brain infarction. J Neurol Science 2010; 297: 6-15.

10. Amaco S, Urrax, Gomez-Choco $\mathrm{M}$, et al.. Uric Acid Levels are relevant in patients with stroke treated with thrombolysis. Stroke 2011: 42 (1) : 528-32.
11. D. W. Powers. Assessment of the stroke patient using the NIH stroke scale. Emerg. Med. Serv 2001;30:52-6.

12. Lloyd-Jones D, Adams RJ, Brown TM et al.. Executive summary: heart disease and stroke statistics-2010 update: a report from the American Heart Association. Circulation 2010; 121: 948-54.

13. Alexander $\mathrm{S}$, Bernard T. Uric acid transport and disease. J Clin Invest 2010;120 (6):1791-9.

14. Logallo N, Naess H, Idicula TT, et al.. Serum uric acid: neuroprotection in thrombolysis. The Bergen NORSTROKE Study. BMC Neurology 2011;11:114.

15. Yadav SK, Nepal N, Niroula D. Prevalence of hyperuricemia among people of morang district of nepal. Journal of Nobel Medical College. 2014;13;3(1):16-21.

16. Yu-F. Wang, J.-X. Li, X.-S. Sun, R. Lai, and W.-L. Sheng. High serum uric acid levels are a protective factor against unfavourable neurological functional outcome in patients with ischaemic stroke. J. Int. Med. Res 2018;46:18261838.

17. Zheng X, Wei Q, Long J, Gong L, Chen H, Luo R, et al.. Gender-specific association of serum uric acid levels and cardio-ankle vascular index in Chinese adults. Lipids Health Dis 2018;17:80.

18. Kawabe M, Sato A, Hoshi T, Sakai S, Hiraya D, Watabe $\mathrm{H}$, et al.. Gender differences in the association between serum uric acid and prognosis in patients with acute coronary syndrome. J Cardiol 2016;67:170-6.

19. Bhadraj, Makor DS, Seth S, et al.. Uric Acid in men with acute stroke. Int J Interdis and Multidisci Studies 2015; 2(5): 146-52.

20. Shah Harsh, Patange Aparna. The study of serum uric acid levels in ischemic stroke patients. International Journal of Contemporary Medical Research 2019;6(1):A16-A20.

21. Li J, Muraki I, Imano H, Cui R, Yamagishi K, Umesawa $\mathrm{M}$, et al.. Serum uric acid and risk of stroke and its types: the Circulatory Risk in Communities Study (CIRCS). Hypertens Res. 2020

22. A. Karagiannis, D. P. Mikhailidis. Serum uric acid as an independent predictor of early death after acute stroke. Circ. J 2017;71:1120-1127.

23. Kim SY, Guevara P, Kim KM, et al.. Hyperuricemia and risk of stroke: a systematic review and meta-analysis. Arthritis Rheum 2009; 61(7):885-892.

24. Li P, Zhang L, Zhang M, Zhou C, Lin N. Uric acid enhances PKC-dependent eNOS phosphorylation and mediates cellular ER stress: A mechanism for uric acidinduced endothelial dysfunction. Int $\mathrm{J}$ Mol Med. 2016;37:989

\section{Source of Support: None Declared Conflict of Interest: None Declared}

\section{Policy for Articles with Open Access:}

Authors who publish with MedPulse International Journal of Medicine, Print ISSN: 2550-7583, Online ISSN: 2636-4751 agree to the following terms: Authors retain copyright and grant the journal right of first publication with the work simultaneously licensed under a Creative Commons Attribution License that allows others to share the work with an acknowledgement of the work's authorship and initial publication in this journal.

Authors are permitted and encouraged to post links to their work online (e.g., in institutional repositories or on their website) prior to and during the submission process, as it can lead to productive exchanges, as well as earlier and greater citation of published work. 